\title{
Impact of COVID-19 Pandemic on Ophthalmic Presentations to an Australian Outer Metropolitan and Rural Emergency Department: A Retrospective Comparative Study
}

King Fai Calvin Leung ( $\sim$ kfcalvinl@gmail.com )

Campbelltown Hospital

Mojtaba Golzan

University of Technology Sydney (UTS)

Chaminda Egodage

Campbelltown Hospital

Simon Rodda

Bowral and District Hospital

Richard Cracknell

Campbelltown Hospital

Peter Macken

Bowral and District Hospital

Shweta Kaushik

Campbelltown Hospital

\section{Research Article}

Keywords: COVID-19, epidemiology, emergency medicine, ophthalmic emergencies, tele-ophthalmology

Posted Date: August 2nd, 2021

DOI: https://doi.org/10.21203/rs.3.rs-690092/v1

License: (1) This work is licensed under a Creative Commons Attribution 4.0 International License. Read Full License

Version of Record: A version of this preprint was published at BMC Ophthalmology on January 28th, 2022. See the published version at https://doi.org/10.1186/s12886-022-02271-8. 


\section{Abstract \\ Background}

To analyse ophthalmic presentations to an outer metropolitan and a rural emergency department (ED) during the COVID-19 pandemic in New South Wales (NSW), Australia.

\section{Methods}

A retrospective comparative study of ophthalmic emergency presentations to Campbelltown Hospital (fifth busiest NSW metropolitan ED; population 310,000) and Bowral and District Hospital (rural ED; population 48,000 ) before and during COVID-19 was conducted. Patient demographics, triage category, referral source, diagnosis, length of stay, departure status, and follow-up location were assessed from coding data between March 1st to May 31st in 2019 and 2020, corresponding to the peak case numbers and restrictions during COVID-19 in NSW. Differences before and during COVID-19 were analysed using chi-squared tests or independent sample t-tests.

\section{Results}

There was no change in ophthalmic presentations at Campbelltown $(n=228$ in 2019 vs. $n=232$ in 2020; $+1.75 \%, p=0.12)$ and an increase at Bowral $(n=100$ in 2019 vs. $n=111$ in 2020; $+11 \%, p<0.01)$ during COVID19. Urgent ophthalmic presentations (Triage Category 3 ) decreased at Bowral $(p=0.0075)$, while non-urgent ophthalmic presentations (Triage Category 5) increased at both hospitals (Campbelltown $p<0.05$, Bowral $p<$ 0.01).

\section{Conclusions}

An upward and varied trend in ophthalmic presentations to an outer metropolitan and a rural ED was observed. Heterogeneous ophthalmic presentation trends at peripheral EDs suggest that a high demand for ophthalmic services remained. A flexible healthcare delivery strategy, such as tele-ophthalmology, may optimise patient care during and after COVID-19.

\section{Background}

The COVID-19 pandemic has significantly impacted health care systems worldwide and resulted in radical changes to service provision. Since the introduction of lockdowns and other restrictions during the height of the pandemic, there has been a general reduction in adult and paediatric attendances to emergency departments $(E D s)^{1-9}$. The fear of contagion and social gathering restrictions in response to SARS-CoV-2 may have caused patients to avoid seeking medical attention or may have limited their access to care for non-COVID-19 illnesses ${ }^{7,10}$. A similar trend has been observed for eye-care with various studies reporting a reduction in ophthalmic-related presentations to $\mathrm{EDs}^{11-17}$. 
The ocular surface has been proposed as a site of exposure and infection by SARS-CoV- $2^{18}$. The Ophthalmological community has responded in part by reinforcement of PPE use, change in triaging for operative procedures, and the increased use of telemedicine services ${ }^{19-21}$. Pre-COVID-19 studies have found that patients commonly present to the ED with conjunctivitis, corneal abrasion, keratitis, iridocyclitis, or symptoms secondary to cataracts ${ }^{22}$; with a significant number of patients having conditions that may be managed in a primary care setting ${ }^{23}$.

In comparison to other countries, the closure of international borders in Australia on 20th March lead to a lull in new COVID-19 diagnoses between late March to May in New South Wales (NSW) ${ }^{24}$. Despite this, it has been proposed that the anxiety of presenting to the ED during this period may have led to a reduction in ophthalmic presentation numbers at several metropolitan Australian EDs ${ }^{13}$.

It is unclear if this pattern of presentations is replicated in other busier, outer metropolitan locations or in rural EDs. With a number of reports suggesting a growing trend of metropolitan workers relocating to regional areas during the pandemic, it would be valuable to measure whether such redistribution of population had an impact on local EDs. An understanding of how COVID-19 has affected the presentation and management of patients with ophthalmic conditions to both metropolitan and rural EDs in Australia may assist in appropriate medical resource allocation during pandemics and reveal areas that may be enriched by new and innovative approaches to ophthalmic care delivery. The aim of this study was to assess the changes in ophthalmic presentations to an outer metropolitan ED and a rural ED during the period corresponding to the peak case numbers and restrictions for COVID-19 in NSW, from March 1st to May 31st .

\section{Methods}

Our study focused on two EDs, Campbelltown Hospital and Bowral and District Hospital, located within South Western Sydney Local Health District (SWSLHD). SWSLHD covers seven Local Government Areas (LGA), serving a population of approximately 820,000 people. Campbelltown Hospital ED (Modified Monash 1) is the major 40-bed metropolitan Level 5 emergency service for the Macarthur area, which includes the LGAs of Campbelltown, Camden, and Wollondilly Shire, with a population close to 310,000. Bowral and District Hospital ED (Modified Monash 3 ) is a Level 3 rural ED serving the Southern Highlands region with a population of around 48,000. Its ED has 10 beds. The Modified Monash Model is used by the Australian Government to define whether a location is metropolitan (Modified Monash 1) or very remote (Modified Monash 7).

Patients presenting with an ophthalmic-related issue to either EDs are first reviewed by the emergency doctor and referred to the on-call Ophthalmologist if required. For Campbelltown Hospital, this occurs during work hours (for review in private rooms or in hospital), or after-hours to the ophthalmology registrar at the linked Tertiary referral facility in the Local Health District (Liverpool Hospital), which has an outpatient eye clinic. During workhours and after-hours, ophthalmic referrals from Bowral ED are sent to a single ophthalmology practice for review in the private rooms or in hospital.

A list of ophthalmic-related presentations from these two SWSLHD EDs were retrospectively obtained from the electronic medical records and ED coding data. Dates of inclusion were from 1st March to 31 st May for 2019 and 2020. Further visit data were obtained from auditing of individual patient notes. Variables obtained included patient demographics, triage category for each presentation, discharge diagnosis (based on 
International Classification of Diseases, tenth revision [ICD-10] and SNOMED CT terminology), length of stay in the emergency department, source of referral, departure status, follow-up disposition at discharge, and whether the patient was referred to an Ophthalmology service. Similar discharge diagnoses were grouped together. This includes all ocular surface foreign bodies as "foreign body", changes in vision as "visual disturbance", and bacterial or viral conjunctivitis as "acute conjunctivitis". To avoid an exhaustive list of diagnoses, only diagnoses that had 3 or more presentations in 2019 or 2020 were included.

Data analysis was performed in Microsoft Excel v16.0. Descriptive statistics including percentage change in presentations between 2019 and 2020 were calculated. Percentage change was calculated by dividing the difference between the numbers in 2019 and 2020 with the number in 2019 for each variable. Comparison groups between 2019 and 2020 were analysed with chi-squared tests or independent samples t-tests.

This study was approved by the South Western Sydney Local Health District Human Research Ethics Committee (2020/ETH02045) and was conducted in accordance with the tenets of the Declaration of Helsinki. All patient details were anonymised during data collection.

\section{Results}

A significant decrease in the total number of presentations to both EDs in 2020 (compared with 2019) was observed (21314 in 2019 vs. 18054 in 2020 at Campbelltown ED [15.3\% decrease], and 5123 in 2019 vs. 4178 at Bowral ED [18.45\% decrease]; both $p<0.01$; Table 1). However, there was no reduction in the number of ophthalmic-related emergency presentations at Campbelltown Hospital ED during the height of the COVID-19 pandemic (228 in 2019 vs. 232 in 2020, 1.75\% increase, p = 0.12, Table 1). On the other hand, there was an 11\% increase in ophthalmic presentations at Bowral Hospital ED from March to May in 2020 (100 in 2019 vs. 111 in 2020, $p<0.01)$. Both hospitals had an increase in non-urgent (Triage Category 5) ophthalmic presentations ( $p=$ 0.03 for Campbelltown, $p<0.01$ for Bowral), whilst Bowral hospital also had a $50 \%$ decrease in urgent (Triage Category 3) ophthalmic-related presentations in March to May of $2020(p=0.0075)$. There was no change in presentation numbers for other triage categories at both EDs (all $p>0.05$, Table 1 ). 
Table 1

Ophthalmic-related presentation characteristics at Campbelltown and Bowral Emergency Departments (March1st to May-31st, 2019 and 2020).

\begin{tabular}{|c|c|c|c|c|c|c|c|c|}
\hline & \multicolumn{4}{|c|}{ Campbelltown Hospital } & \multicolumn{4}{|c|}{ Bowral and District Hospital } \\
\hline & 2019 & 2020 & $\begin{array}{l}\% \\
\text { change }\end{array}$ & $\begin{array}{l}\mathrm{p} \\
\text { value }\end{array}$ & 2019 & 2020 & $\begin{array}{l}\% \\
\text { change }\end{array}$ & $p$ value \\
\hline $\begin{array}{l}\text { Ophthalmic-Related } \\
\text { Presentations }(\mathrm{n})\end{array}$ & 228 & 232 & 1.75 & 0.12 & 100 & 111 & 11 & $0.00059 *$ \\
\hline $\begin{array}{l}\text { Total Department } \\
\text { Presentations }(n)\end{array}$ & 21314 & 18054 & -15.30 & ¿.01* & 5123 & 4178 & -18.45 & $<0.01^{*}$ \\
\hline Age (mean \pm SD; years) & $\begin{array}{l}32 \pm \\
22\end{array}$ & $\begin{array}{l}35 \pm \\
21\end{array}$ & 9.07 & 0.075 & $\begin{array}{l}38 \pm \\
20\end{array}$ & $\begin{array}{l}42 \pm \\
23\end{array}$ & 12.10 & 0.061 \\
\hline Gender (females; n) & 86 & 77 & -10.47 & 0.41 & 33 & 35 & 6.06 & 0.85 \\
\hline $\begin{array}{l}\text { Aboriginal and Torres } \\
\text { Strait Islander (n) }\end{array}$ & 11 & 11 & 0 & 0.97 & 4 & 6 & 50 & 0.64 \\
\hline \multicolumn{9}{|l|}{ Triage Category (n) } \\
\hline 1 -Resuscitation & 0 & 0 & 0 & - & 0 & 0 & 0 & - \\
\hline 2 - Emergency & 7 & 7 & 0 & 0.97 & 2 & 3 & 50 & 0.74 \\
\hline 3 - Urgent & 54 & 51 & -5.56 & 0.70 & 32 & 16 & -50 & $0.0075^{*}$ \\
\hline 4 -Semi-Urgent & 128 & 113 & -11.72 & 0.27 & 63 & 73 & 15.87 & 0.80 \\
\hline 5 - Non-urgent & 39 & 61 & 56.41 & $0.03^{*}$ & 3 & 19 & 533.33 & $0.0015^{*}$ \\
\hline $\begin{array}{l}\text { Length of Stay (mean } \pm \\
\text { SD; minutes) }\end{array}$ & $\begin{array}{l}229 \pm \\
162\end{array}$ & $\begin{array}{l}148 \pm \\
95\end{array}$ & -35.52 & ¿.01* & $\begin{array}{l}128 \\
\pm 91\end{array}$ & $\begin{array}{l}119 \\
\pm 92\end{array}$ & -7.082 & 0.24 \\
\hline \multicolumn{9}{|l|}{ Source of Referral (n) } \\
\hline GP/Dentist & 59 & 63 & 6.78 & 0.79 & 7 & 2 & -71.43 & 0.068 \\
\hline Self/Family/Friends & 160 & 153 & -4.38 & 0.58 & 90 & 107 & 18.89 & 0.63 \\
\hline Employer & 1 & 3 & 200 & 0.33 & - & - & - & - \\
\hline Nursing Home & 1 & 0 & -100 & 0.31 & - & - & - & - \\
\hline Community Health & 1 & 0 & -100 & 0.31 & - & - & - & - \\
\hline Emergency Dept & 0 & 3 & - & 0.09 & 2 & 0 & -100 & 0.14 \\
\hline Other Hospital & 2 & 3 & 50 & 0.67 & 0 & 1 & - & 0.34 \\
\hline Outpatient Department & 1 & 0 & -100 & 0.31 & - & - & - & - \\
\hline Specialist & 0 & 3 & - & 0.09 & - & - & - & - \\
\hline Other & 3 & 4 & 33.33 & 0.72 & 1 & 1 & 0 & 0.94 \\
\hline
\end{tabular}


At Campbelltown Hospital ED, the number of patients who did not wait to be seen or left at their own risk with ophthalmic presentations decreased during COVID-19 ( $p=0.049$ and 0.0091 , Table 2$)$, and the average length of stay also reduced in 2020 for those with ophthalmic conditions $(p<0.01$, Table 1$)$. There was no change in numbers for other departure statuses at Campbelltown ED (all $p>0.05$, Table 2). Similarly, there was no significant change in all departure statuses and length of stay for ophthalmic presentations at Bowral and District Hospital ED (all $p>0.05$, Tables 1 and 2). Source of referral of patients at both EDs did not change (all $\mathrm{p}>0.05$, Table 1). 
Table 2

Ophthalmic-related presentation disposition patterns at Campbelltown and Bowral Emergency Departments (March-1 st to May-31st, 2019 and 2020).

\begin{tabular}{|c|c|c|c|c|c|c|c|c|}
\hline & \multicolumn{4}{|c|}{ Campbelltown Hospital } & \multicolumn{4}{|c|}{ Bowral and District Hospital } \\
\hline & 2019 & 2020 & $\begin{array}{l}\% \\
\text { change }\end{array}$ & p value & 2019 & 2020 & $\begin{array}{l}\% \\
\text { change }\end{array}$ & $p_{\text {value }}$ \\
\hline \multicolumn{9}{|l|}{ Departure status (n) } \\
\hline Treatment complete & 162 & 188 & 16.05 & 0.22 & 88 & 98 & 11.36 & 0.98 \\
\hline Admitted to ED Short Stay Unit & 0 & 2 & - & 0.16 & - & - & - & - \\
\hline Admitted to ward & 20 & 18 & -10 & 0.71 & 1 & 1 & 0 & 0.94 \\
\hline Transferred to another hospital & 2 & 5 & 150 & 0.27 & 0 & 2 & - & 0.18 \\
\hline Did not wait to be attended & 10 & 3 & -70 & $0.049 *$ & 11 & 10 & -9.091 & 0.65 \\
\hline Left at own risk & 34 & 16 & -52.94 & $0.0091^{*}$ & - & - & - & - \\
\hline \multicolumn{9}{|l|}{ Follow-up Location (n) } \\
\hline$G P / L M O$ & 106 & 121 & 14.15 & 0.39 & 56 & 49 & -12.5 & 0.22 \\
\hline AMO/Specialist & 19 & 12 & -36.84 & 0.19 & 17 & 21 & 23.53 & 0.74 \\
\hline Medical Practice (not Psych) & 14 & 10 & -28.57 & 0.39 & 0 & 1 & - & 0.34 \\
\hline Outpatients (non-psychiatric) & 28 & 37 & 32.14 & 0.30 & 1 & 1 & 0 & 0.94 \\
\hline Review in ED - Planned & 5 & 2 & -60 & 0.25 & 3 & 2 & -33.33 & 0.57 \\
\hline Review in ED - PRN & 9 & 14 & 55.56 & 0.32 & 8 & 12 & 50 & 0.51 \\
\hline Not referred & 31 & 15 & -51.61 & $0.016 *$ & 13 & 22 & 69.23 & 0.22 \\
\hline Unknown & 7 & 2 & -71.43 & 0.090 & - & - & - & - \\
\hline Other & 9 & 19 & 111.11 & 0.065 & 2 & 3 & 50 & 0.74 \\
\hline $\begin{array}{l}\text { Referred to Ophthalmology } \\
\text { Service (n) }\end{array}$ & 58 & 63 & 8.62 & 0.72 & 18 & 16 & -11.11 & 0.52 \\
\hline
\end{tabular}

Patients who were not referred to any follow-up service at discharge decreased at Campbelltown Hospital ED during COVID-19 ( $p=0.016$, Table 2). However, this result may be explained by the fact that there was also a reduction in patients who had left at their own risk or did not wait to be seen (who were not referred for followup as they left prior to ED medical assessment). There was no significant change in all other follow-up patterns including referral to an ophthalmology service at both hospitals during COVID-19 (all p >0.05, Table 2). There was no change in patient demographics (age, gender, proportion identifying as Aboriginal and Torres Strait Islanders) between the two time points at both Campbelltown and Bowral EDs (all p >0.05, Table 1). 
At both hospitals and during both 2019 and 2020, the main discharge diagnoses included anterior segment issues such as foreign bodies, corneal abrasions, conjunctivitis, corneal chemical injuries, eye pain, and periorbital cellulitis (Table 3). There was a significant decrease in the number of patients presenting with visual disturbance at Campbelltown Hospital ED in 2020 (14 vs. 4, -71\% change, $p=0.017$, Table 3). There were also more periocular allergic reactions at Campbelltown Hospital ED in 2020 ( $p=0.047)$. There were no significant changes in the types of ophthalmic presentations to Bowral and District Hospital ED. 
Table 3

Ophthalmic-related discharge diagnoses at Campbelltown and Bowral Emergency Departments (March-1st to May-31st, 2019 and 2020).

\begin{tabular}{|c|c|c|c|c|c|c|c|c|c|}
\hline \multicolumn{5}{|c|}{ Campbelltown Hospital } & \multicolumn{5}{|c|}{ Bowral and District Hospital } \\
\hline $\begin{array}{l}\text { Discharge } \\
\text { Diagnosis }\end{array}$ & 2019 & 2020 & $\begin{array}{l}\% \\
\text { change }\end{array}$ & $\begin{array}{l}\mathrm{p} \\
\text { value }\end{array}$ & $\begin{array}{l}\text { Discharge } \\
\text { Diagnosis }\end{array}$ & 2019 & 2020 & $\begin{array}{l}\% \\
\text { change }\end{array}$ & $\begin{array}{l}\mathrm{p} \\
\text { value }\end{array}$ \\
\hline Foreign body & 39 & 58 & 48.72 & 0.065 & Foreign body & 24 & 29 & 20.83 & 0.76 \\
\hline $\begin{array}{l}\text { Corneal } \\
\text { abrasion }\end{array}$ & 18 & 20 & 11.11 & 0.787 & $\begin{array}{l}\text { Corneal } \\
\text { abrasion }\end{array}$ & 10 & 14 & 40.00 & 0.57 \\
\hline $\begin{array}{l}\text { Acute } \\
\text { conjunctivitis }\end{array}$ & 13 & 19 & 46.15 & 0.312 & $\begin{array}{l}\text { Chemical injury } \\
\text { to cornea }\end{array}$ & 3 & 8 & 166.67 & 0.18 \\
\hline $\begin{array}{l}\text { Periorbital } \\
\text { cellulitis }\end{array}$ & 9 & 15 & 66.67 & 0.237 & Eye pain & 5 & 4 & -20.00 & 0.62 \\
\hline Eye pain & 12 & 12 & 0.00 & 0.966 & Red eye & 3 & 4 & 33.33 & 0.81 \\
\hline $\begin{array}{l}\text { Chemical } \\
\text { injury to } \\
\text { cornea }\end{array}$ & 9 & 12 & 33.33 & 0.539 & $\begin{array}{l}\text { Acute } \\
\text { conjunctivitis }\end{array}$ & 6 & 3 & -50.00 & 0.25 \\
\hline Red eye & 4 & 8 & 100.00 & 0.261 & Eye swelling & 0 & 3 & - & 0.10 \\
\hline Corneal ulcer & 3 & 5 & 66.67 & 0.495 & Headache & 2 & 3 & 50.00 & 0.74 \\
\hline $\begin{array}{l}\text { Visual } \\
\text { disturbance }\end{array}$ & 14 & 4 & -71.43 & $0.017 *$ & $\begin{array}{l}\text { Periorbital } \\
\text { cellulitis }\end{array}$ & 4 & 3 & -25.00 & 0.61 \\
\hline $\begin{array}{l}\text { Laceration of } \\
\text { eyelid }\end{array}$ & 9 & 4 & -55.56 & 0.156 & $\begin{array}{l}\text { Subconjunctival } \\
\text { haemorrhage }\end{array}$ & 2 & 3 & 50 & 0.74 \\
\hline $\begin{array}{l}\text { Blunt injury } \\
\text { of eye }\end{array}$ & 8 & 4 & -50.00 & 0.236 & $\begin{array}{l}\text { Blunt injury of } \\
\text { eye }\end{array}$ & 3 & 2 & -33.33 & 0.57 \\
\hline $\begin{array}{l}\text { Welder's } \\
\text { flash }\end{array}$ & 1 & 4 & 300.00 & 0.186 & $\begin{array}{l}\text { Visual } \\
\text { disturbance }\end{array}$ & 3 & 1 & -66.67 & 0.27 \\
\hline $\begin{array}{l}\text { Allergic } \\
\text { reaction }\end{array}$ & 0 & 4 & - & $0.047^{*}$ & & & & & \\
\hline $\begin{array}{l}\text { Allergic } \\
\text { conjunctivitis }\end{array}$ & 2 & 3 & 50.00 & 0.669 & & & & & \\
\hline Burn of eye & 1 & 3 & 200.00 & 0.326 & & & & & \\
\hline Stye & 7 & 2 & -71.43 & 0.090 & & & & & \\
\hline $\begin{array}{l}\text { Discharge } \\
\text { from eye }\end{array}$ & 5 & 2 & -60.00 & 0.247 & & & & & \\
\hline Eye swelling & 4 & 1 & -75.00 & 0.173 & & & & & \\
\hline Blepharitis & 3 & 0 & -100.00 & 0.081 & & & & & \\
\hline
\end{tabular}




\section{Discussion}

In this retrospective study, we investigated the impact of the COVID-19 pandemic on ophthalmic presentations to the ED of a busy outer metropolitan and a rural hospital. Results demonstrated that there was no change in total ophthalmic presentation numbers to an outer metropolitan ED (Campbelltown Hospital) and an increase in ophthalmic cases presenting to a rural ED (Bowral and District Hospital) during the pandemic from March 1 st to May 31st of 2020, in comparison to the same period in 2019. Surprisingly, both departments saw a corresponding decrease in total emergency presentations during this time period in 2020. With regards to ophthalmic presentations, there was an increase in non-urgent (Triage Category 5) presentations to both EDs, and a decrease in patients presenting with more serious issues such as visual disturbance. In Campbelltown Hospital, we found that there were fewer patients with ophthalmic conditions that did not wait to be seen, as well as a decrease in the length of stay for ophthalmic presentations, however these findings were not replicated in Bowral and District Hospital. On the other hand, Bowral ED saw a significant decrease in urgent (Triage Category 3) ophthalmic-related presentations.

Our finding that total ophthalmic presentation numbers remained unchanged for Campbelltown ED and increased at Bowral ED during COVID-19 is interesting, as it contrasts with other studies that had demonstrated a decline in ophthalmic ED presentations during the pandemic ${ }^{11-17}$. In particular, a similar analysis conducted in NSW by Kam et al. ${ }^{13}$ demonstrated a fall of $16 \%$ in ophthalmic presentations during a similar time period of 29th March to 31 st May at the metropolitan EDs of Western Sydney Local Health District (WSLHD), with return of presentation numbers to those of 2019 in June to July after easing of restrictions. Compared with the hospitals explored in their study, Campbelltown Hospital receives a greater number of patient presentations per year and is more peripherally located in Sydney ${ }^{25}$, whilst Bowral and District Hospital is a rural hospital southwest of Sydney with fewer per annum presentations. A potential reason for the difference in ophthalmic presentation numbers in our study may be due to the difference in geographical location of these hospitals. There may have been differing perception of sites more affected by COVID-19 amongst the populace, secondary to proximity of identified cases to specific hospitals. This may have affected presentation patterns to these locations. Population relocation to more regional areas ${ }^{26}$ due to increasing ability of citizens to work from home may have also resulted in an increase in ophthalmic presentations in outer metropolitan and rural hospitals.

Interestingly we found a significant increase in non-urgent (Triage Category 5) presentations to Campbelltown and Bowral EDs in 2020. A breakdown of discharge diagnoses for Category 5 presentations demonstrated that the majority of this increase was due to ocular surface trauma and eye pain (An additional table shows this in more detail [see Additional file 1]). A reason for this may be the reduced access to primary care providers such as general practitioners (GP) or optometrists during the start of the pandemic in NSW and the limitations of GP telemedicine for these eye condition ${ }^{27}$. The subjective patient-perceived urgency of their condition, due to ocular surface discomfort and pain, may therefore have caused an increase in ocular surface issues presenting to the emergency department.

In Bowral, there was reduced access to the private ophthalmology referral practice for non-urgent cases during early March 2020 due to physician leave, whilst available ophthalmologists saw urgent cases only. This may also explain the increase in non-urgent ophthalmic presentations during the pandemic at Bowral ED. There was

Page 10/15 
also an agreement between Bowral Hospital and the private ophthalmology practice for patients to be directly reviewed in the private ophthalmology rooms as part of the initial pandemic response in April 2020. Despite the introduction of this referral pathway, our data analysis demonstrated that there was no month-over-month change in ophthalmic presentation and referral patterns in 2020, and many patients presenting to Bowral ED with ophthalmic issues during COVID-19 were still being reviewed by emergency doctors, with only three patients lacking medical assessment documentation during our study period.

Consistent with previous studies, which have shown a drop in presentations for retinal detachments and other causes of visual acuity change or loss ${ }^{11-13}$, there was a significant decrease in patients presenting with visual disturbances at Campbelltown Hospital ED in our study. There was also a decrease in visual disturbance presentations at Bowral Hospital, but this did not reach significance. As aforementioned, for patients, ocular pain may have eclipsed visual disturbance as an important reason to present to ED during COVID-19. A reduction in identification of patients with visual disturbance may have profound effects on the ongoing burden of vision loss as the pandemic resolves.

There were significantly fewer patients in 2020 at Campbelltown Hospital who left the department before medical assessment, which was also reported by Kam et al. ${ }^{13}$. This may have been due to a general decrease in case numbers across the emergency department, leading to fewer patients waiting, and was further supported in our study by the significant reduction in length of stay of patients presenting with ophthalmic issues at Campbelltown Hospital. On the other hand, there was no change in the length of stay and number of patients presenting with ophthalmic issues who did not wait for assessment at Bowral ED. This is in the context of increased total ophthalmic-related presentations to this rural ED during 2020, and likely reflects its more streamlined ophthalmological referral pathway that existed prior to the pandemic, for which the private ophthalmology rooms are situated close to the hospital. In contrast to this, patients presenting to the more metropolitan Campbelltown Hospital must utilise private transportation to attend private ophthalmology rooms for review. There was no change in the number of patients being referred for ophthalmology follow-up at both hospitals, suggesting that referral patterns at both EDs did not change significantly with COVID-19, despite changes in types of presentations.

There are several limitations to this study. As a retrospective study of only ED coding data and documentation, the discharge diagnoses of each presentation may not be accurate and does not reflect the final diagnoses made by an ophthalmologist for those patients that received formal specialist review after discharge. However, our study replicated methods used by similar studies ${ }^{13}$, which did not analyse documentation from ophthalmology follow-up visits. There may also be potential changes in triage criteria in response to the COVID19 pandemic, as suggested by the differences in discharge diagnoses per triage category in both EDs (An additional table shows this in more detail [see Additional file 1]).

Despite these limitations, our audit incorporates data from two EDs that differ by locality and acuity, which allowed for a comparison of the effect of COVID-19 on ophthalmic ED presentations across NSW. The inclusion of two hospital EDs also increased the sample size of our audit. We had also ensured that the coded discharge diagnoses were correct via individual patient chart reviews of their emergency department presentation, increasing the accuracy of our analysed data. 


\section{Conclusions}

Our findings suggest that there was a heterogenous effect of COVID-19 on ophthalmic presentation trends in different parts of NSW. Thus, patients may have received inconsistent and non-uniform healthcare due to changes in healthcare service availability during the pandemic. Especially concerning is the reduction in patients presenting with visual disturbance, which may have significant long-term public health implications by increasing the burden of vision loss as we recover from the pandemic.

Compared with other countries, Australia has had fewer cases of COVID-19 per capita ${ }^{28}$. It is therefore difficult to directly compare our results with studies conducted in other countries. Nevertheless, our study indicates that the pandemic has noticeably influenced patients seeking healthcare for ophthalmic conditions in Australia, as seen by the changes in urgent and non-urgent presentations during COVID-19. The varied effects of the pandemic on ophthalmic emergency presentations across NSW suggests that current methods of ophthalmic care delivery are inadequate during a pandemic. There may be a need for an alternative and more flexible ophthalmic healthcare delivery strategy linked to different geographical locations. With the rise in non-urgent (Triage Category 5) ophthalmic presentations in more regional communities, and a reduction in patients seeking care for more sight-threatening symptoms, alternative avenues of care such as tele-ophthalmology may become more ubiquitous and advantageous during and after the pandemic to improve management of these presentations. Our research group is currently developing such a tele-ophthalmology response for ED ophthalmic patients, with consideration of constraints presented by the COVID-19 pandemic.

\section{List Of Abbreviations}

ED Emergency Department

GP General Practitioner

ICD-10 International Classification of Diseases 10th Revision

LGA Local Government Area

NSW New South Wales

SWSLHD South Western Sydney Local Health District

WSLHD Western Sydney Local Health District

\section{Declarations}

\section{Ethics approval and consent to participate}

This study was approved by the South Western Sydney Local Health District Human Research Ethics Committee (2020/ETH02045) and was conducted in accordance with the tenets of the Declaration of Helsinki.

\section{Consent for publication}


Not applicable.

\section{Availability of data and materials}

All data generated or analysed during this study are included in this published article (and its supplementary information files). Further information is available from the corresponding author on reasonable request.

\section{Competing interests}

The authors declare that they have no competing interests.

\section{Funding}

None of the authors have any financial support related to this submission.

\section{Authors' contributions}

KFCL collected and analysed the coding data for ophthalmic emergency presentations, prepared all tables, and was a major contributor in writing the manuscript. MG contributed to analysis and interpretation of the data and assisted in editing of the manuscript. SK contributed to study design, data interpretation, and manuscript editing. All authors read and approved the final manuscript.

\section{Acknowledgements}

We would like to thank Amanda Bendeich (Data Manager, Emergency Department, Campbelltown and Camden Hospitals) for her help in extracting emergency presentation data from the electronic medical records.

\section{References}

1. Chaiyachati BH, Agawu A, Zorc JJ, Balamuth F. Trends in Pediatric Emergency Department Utilization after Institution of Coronavirus Disease-19 Mandatory Social Distancing. J Pediatr. 2020;226:274-277.

2. De Filippo O, D'Ascenzo F, Angelini F, et al. Reduced Rate of Hospital Admissions for ACS during Covid-19 Outbreak in Northern Italy. N Engl J Med. 2020;383(1):88-89.

3. Dragovic M, Pascu V, Hall T, Ingram J, Waters F. Emergency department mental health presentations before and during the COVID-19 outbreak in Western Australia. Australas Psychiatry. 2020;28(6):627-631.

4. Hartnett KP, Kite-Powell A, DeVies J, et al. Impact of the COVID-19 Pandemic on Emergency Department Visits - United States, January 1, 2019-May 30, 2020. MMWR Morb Mortal Wkly Rep. 2020;69(23):699704.

5. Kam AW, Chaudhry SG, Gunasekaran N, White AJ, Vukasovic M, Fung AT. Fewer presentations to metropolitan emergency departments during the COVID-19 pandemic. Med J Aust. 2020;213(8):370-371.

6. Roland D, Harwood R, Bishop N, Hargreaves D, Patel S, Sinha I. Children's emergency presentations during the COVID-19 pandemic. Lancet Child Adolesc Health. 2020;4(8):e32-e33.

7. Rosenbaum L. The Untold Toll - The Pandemic's Effects on Patients without Covid-19. N Engl J Med. 2020;382(24):2368-2371. 
8. Uchino K, Kolikonda MK, Brown D, et al. Decline in Stroke Presentations During COVID-19 Surge. Stroke. 2020;51(8):2544-2547.

9. Westgard BC, Morgan MW, Vazquez-Benitez G, Erickson LO, Zwank MD. An Analysis of Changes in Emergency Department Visits After a State Declaration During the Time of COVID-19. Ann Emerg Med. 2020;76(5):595-601.

10. Jennings GL. Coronavirus disease 2019 (COVID-19): angiotensin-converting enzyme inhibitors, angiotensin II receptor blockers and cardiovascular disease. Med J Aust. 2020;212(11):502-503 e501.

11. Wickham L, Hay G, Hamilton R, et al. The impact of COVID policies on acute ophthalmology servicesexperiences from Moorfields Eye Hospital NHS Foundation Trust. Eye (Lond). 2020;34(7):1189-1192.

12. Shams F, El-Abiary M, Goudie C, Yorston D. Effects of lockdown on retinal detachment incidence in Scotland. Eye (Lond). 2020.

13. Kam AW, Gunasekaran N, Chaudhry SG, Vukasovic M, White AJ, Fung AT. Reduction in Ophthalmic Presentations to Australian Emergency Departments During the COVID-19 Period: Are We Seeing the Full Picture? Clinical Ophthalmology. 2021;15:341-346.

14. Poyser A, Deol SS, Osman L, et al. Impact of COVID-19 pandemic and lockdown on eye emergencies. Eur J Ophthalmol. 2020:1120672120974944.

15. Moon JY, Miller JB, Katz R, et al. The Impact of the COVID-19 Pandemic on Ophthalmic Care at an EyeSpecific Emergency Department in an Outbreak Hotspot. Clin Ophthalmol. 2020;14:4155-4163.

16. Pellegrini M, Roda M, Di Geronimo N, Lupardi E, Giannaccare G, Schiavi C. Changing trends of ocular trauma in the time of COVID-19 pandemic. Eye (Lond). 2020;34(7):1248-1250.

17. Posarelli C, Maglionico MN, Covello G, et al. Ophthalmological emergencies and the SARS-CoV-2 outbreak. PLoS One. 2020;15(10):e0239796.

18. Coroneo MT. The eye as the discrete but defensible portal of coronavirus infection. Ocul Surf. 2020.

19. Gharebaghi R, Desuatels J, Moshirfar M, Parvizi M, Daryabari SH, Heidary F. COVID-19: Preliminary Clinical Guidelines for Ophthalmology Practices. Med Hypothesis Discov Innov Ophthalmol. 2020;9(2):149-158.

20. Lam D, Downie C, Cornish E, McCluskey P, Zagora SL. Telehealth in an acute ophthalmic setting during COVID-19 lock-down. Clin Exp Ophthalmol. 2020;48(9):1312-1315.

21. Safadi K, Kruger JM, Chowers I, et al. Ophthalmology practice during the COVID-19 pandemic. BMJ Open Ophthalmol. 2020;5(1):e000487.

22. Kumar NL, Black D, McClellan K. Daytime presentations to a metropolitan ophthalmic emergency department. Clin Exp Ophthalmol. 2005;33(6):586-592.

23. Hau S, Ioannidis A, Masaoutis P, Verma S. Patterns of ophthalmological complaints presenting to a dedicated ophthalmic Accident \& Emergency department: inappropriate use and patients' perspective. Emerg Med J. 2008;25(11):740-744.

24. McAnulty JM, Ward K. Suppressing the Epidemic in New South Wales. N Engl J Med. 2020;382(21):e74.

25. Bureau of Health Information. Healthcare Quarterly. NSW Health. https://www.bhi.nsw.gov.au/BHI_reports/healthcare_quarterly. Published 2020. Updated September 16, 2020. Accessed February 16, 2021. 
26. Australian Bureau of Statistics. Regional internal migration estimates, provisional. https://www.abs.gov.au/statistics/people/population/regional-internal-migration-estimatesprovisional/sep-2020. Published 2021. Updated February 2, 2021. Accessed March 28, 2021.

27. Sutherland K, Chessman J, Zhao J, et al. Impact of COVID-19 on healthcare activity in NSW, Australia. Public Health Res Pract. 2020;30(4).

28. Roser M, Ritchie H, Ortiz-Ospina E, Hasell J. Coronavirus Pandemic (COVID-19). https://ourworldindata.org/coronavirus. Published 2020. Accessed February 5, 2021.

\section{Supplementary Files}

This is a list of supplementary files associated with this preprint. Click to download.

- Additionalfile1.docx 